\title{
Visión y mirada en las Selvas dánicas del conde de Rebolledo ${ }^{1}$
}

\author{
Pedro Ruiz Pérez \\ Universidad de Córdoba
}

Título: Visión y mirada en las Selvas dánicas del conde de Rebolledo.

Resumen: Un nuevo mundo, no menos cargado de exotismo que el americano, se abre a la experiencia diplomática de Rebolledo en el contexto de las guerras de religión y el ocaso imperial hispano. En su poema, las Selvas dánicas (1655), extiende su mirada sobre la historia y el espacio de las tierras danesas, conformando su visión, además de sobre modelos poéticos, entre la erudición de base humanista y los umbrales de la nueva ciencia experimental, pero teñida siempre su mirada de extrańeza y sentido de exilio o extranjería. Entre los resquicios de estos elementos brota una particular imagen de la maravilla.

Palabras clave: Rebolledo, Selvas dánicas, Poesía descriptiva, Poesía y ciencia, Bajobarroco.

Fecha de recepción: 18/6/2014.

Fecha de aceptación: 27/7/2014.
Title: Vision and Look in the Selvas dánicas by the Earl of Rebolledo.

Abstract: To Rebolledo his diplomatic experience in the context of the religious wars and the Spanish imperial decline opens a new world, full of exoticism no less than the American new lands. In his poem, the Selvas dánicas (1655), extends his view on the history and space of the Danish land, forming their vision, plus about poetic models, including basic humanistic scholarship and thresholds of the new experimental science, but always her look dyed of surprise and sense of exile or foreignness. Between the cracks of these elements a particular image of wonder sprouts.

Key words: Rebolledo, Selvas dánicas, Descriptive poetry, Poetry and science, Low Baroque.

Date of Receipt: 18/6/2014.

Date of Approval: 27/7/2014.

1 El presente artículo forma parte del plan de trabajo del Proyecto I+D+i Poesía hispánica en el bajo barroco (1650-1750). Repertorio, edición, historia, FFI2011-24012 del MINECO. En una primera versión fue presentado en el coloquio Mirabiliratio. Das Wunderbare im Zugriff der Frühneuzeitlichen Vernunft (Universität Münster, diciembre de 2013); la redacción en inglés aparecerá en la revista Euphorion. 


\section{UMBRALES}

A las puertas del siglo XVII, la centuria de la primera gran revolución científica y epistemológica ${ }^{2}$, el valentón del soneto cervantino "se espanta” y maravilla ante el monumento funerario de quien fuera monarca de un imperio donde no se ponía el sol. En el artificioso túmulo se ponía en evidencia la tensión entre la voluntad de poder (y de ostentación) y la fuerza inexorable de la destrucción. Motivo de reflexión para alguno, impulso de la ratio, para el vulgo representado por los dos personajes de la composición dialogada, el catafalco sevillano pertenece al ámbito de la mirabilia y se orienta a la admiratio. Aproximadamente una década después, Góngora inicia su maravillado recorrido por una naturaleza, entre silva y soledad, en camino hacia la historia (que irrumpe en el poema a través del castillo y el episodio de cetrería, al final de la Soledad segunda) con los pasos del peregrino, menos perdidos que confusos. "Espanto" y "confusión" (con los correlatos estilísticos que se mueven entre el manierismo y el barroco) son dos caras, dos gestos en sendas miradas lúcidas ante una realidad en transformación, fruto de unos profundos cambios en las nociones de naturaleza y de artificio y de las relaciones entre ambos polos. La transición a un siglo de maravillas (desde las Wunderkammeren a las nuevas nociones sobre la materia, el mundo y el universo) viene marcada en la poesía hispana por el paso a la silva métrica desde el renacentista, ordenado y arquitectónico soneto, aunque, eso sí, hipertrofiado y desbordado ya en la pluma de Cervantes por el sintomático y expresivo estrambote. La mirabiliratio de lo estrambótico.

Disuelta en la nada oculta tras el artificio o deslumbrante en su fluido esplendor ${ }^{3}$, la realidad, eclipsada por la apariencia, cede su lugar a una pa-

2 El estudio clásico de Paul Hazard, La crisis de la conciencia europea (1680-1715), Madrid, Alianza, 1988, sigue siendo referencia básica en esta perspectiva, actualizada para el caso español, en un período más delimitado, por Jesús Pérez Magallón, Construyendo la modernidad: la cultura española en el «tiempo de los novatores» (1675-1725), Madrid, CSIC, 2002.

3 "Fuese, y no hubo nada" concluye el soneto cervantino. En el otro extremo, la doctrina de Epicuro, reivindicada por Rebolledo en su "Papel a D. Juan de Goes", 
labra desbordante, que pasa de su estricta condición de signo, transparente indicación de un referente con existencia autónoma real, a convertirse ella misma en objeto, en un objeto artístico, ligada a un nuevo sentido de la inmanencia. Si de la forma del texto, entre el cuadro del soneto y el río de la silva, pasamos a su materia, observamos parecidos desplazamientos. La creciente y un tanto agobiante presencia de la ciudad, protagonista espacial de la comedia y la novela cortesana ${ }^{4}$, busca su contrapeso y su contrapunto, pero ahora, conforme avanza el siglo XVII, lejos del ideal locus amoenus, virgiliano u horaciano, vigente en la centuria anterior, en una bucólica de raíz clásica y formalización renacentista. Impulsada por la creación gongorina, la silva-soledad da cuenta de esa materia informe que subvierte el ordenado cosmos del hilemorfismo aristotélico, para poner en tensión las "pasiones ciudadanas" (aún identificadas con lo amoroso en la auroral composición de Pedro Espinosa) con las "pastoriles boscarechas". De Cervantes a Góngora, rastreamos la crisis de la utopía arcádica, el paso de la serena contemplación luisiana de la sencillez de lo natural al estremecimiento del espanto, mitad maravilla, mitad vértigo ante lo que espera aún demostración de su mensurabilidad. La preocupación por la reducción de la naturaleza y sus leyes a modelos matemáticos se convierte en uno de los pilares de la nueva ciencia y se extiende hasta la empresa de Spinoza para sustentar una ética more geometrica. Puede situarse un punto de partida, en cuanto formulación de una crisis, en la noción cervantina de "espanto", registrada poco después de su soneto en el Tesoro de Covarrubias: "Espantar. Causar horror, miedo o admiración; y dixose espantar, quasi espasmar, de pasmo; o del nombre spectrum, que

incluido como posliminar en la segunda edición, la de sus "obras completas", de su Selva militar y politica (1661), late, a través de los versos del De rerum natura de Lucrecio, en los endecasílabos y heptasílabos de Góngora, imagen de una fluente metamorfosis y sustentados en una novedosa noción de la materia, una materia informe como la silva.

4 La bibliografía sobre el tema es extensa y variada. Cabe citar, entre otros, Giulio Carlo Argan, The Europe of the Capitals, 1600-1700, Ginebra, Albert Skira, 1964; Romolo Runcini, Il sigillo del poeta. La missione del letterato moderno dalle corte alla città nella Spagna del Siglo de Oro, Roma, Solfanello, 1991; Nieves Romero-Díaz, Nueva nobleza, nueva novela: reescribiendo la cultura urbana del barroco, Newark, Juan de la Cuesta, 2002; y Pedro Ruiz Pérez, "La corte como espacio discursivo", Edad de Oro, XVII (1998), pp. 195-211. 
vale fantasma (...). Espantarse, maravillarse. Espantado, atónito, medroso, maravillado". Admiración y maravilla se conjugan con la noción de temor, y en el fondo lo que late es el pasmo, la suspensión ante una visión de lo desmesurado. En la tradición casi mística del pitagorismo, filtrada por la serenidad horaciana, la contemplación deriva en un sentimiento de armonía lindando con lo extático, tal como lo formula fray Luis de León en sus odas; incluso cuando la dimensión mística se pierde, como en fray Luis de Granada, la naturaleza y sus pequeńas maravillas devienen en "símbolo de la fe". Con Cervantes y Góngora, en cambio, asistimos a los primeros síntomas de una quiebra, la del idilio utópico que tiene en la Arcadia su materialización poético-mística más relevante 5 . Disuelta su armonía a partir de la conciencia de su inasibilidad, del alejamiento que el hombre experimenta respecto a ella, el poeta abandona, en términos de Schiller, su condición ingenua, de identidad con el cosmos, para ingresar en el orden de lo sentimental, a partir de la sensación de la pérdida del orden y el desplazamiento de la conciencia al espacio de lo ajeno.

\section{UNA MIRADA DESDE FUERA}

Hacia el ecuador del siglo XVII se sitúan los textos donde un singular personaje, el conde don Bernardino de Rebolledo (1597-1676), registra desde su peculiar posición los cambios epistemológicos que comienzan a manifestarse en las letras hispanas unas cinco décadas antes. La trayectoria vital y poética, también la epistemológica que media entre ambos momentos, viene marcada para nuestro autor por su prolongada y cada vez más penosa estancia fuera de España. Iniciada en 1636 con las primeras misiones diplomáticas y militares en territorios alemanes, la experiencia

5 Retomo la perspectiva de Jean Canavaggio en "Las Arcadias precarias del teatro cervantino: tres avatares del mito pastoril", en El mito en el teatro clásico español, coord. César Oliva y Francisco Ruiz Ramón, Madrid, Taurus, 1988, pp. 141-157; y algunas de las ideas que expuse en El espacio de la escritura. En torno a una poética del espacio del texto barroco, Berna, Peter Lang, 1996. También, para lo relativo a la sensación de melancolía y su plasmación genérica, puede consultarse Pedro Ruiz Pérez, "El discurso elegiaco y la lírica barroca: pérdida y melancolía”, en La Elegía, dir. Begońa López Bueno, Sevilla, Universidad de Sevilla, 1996, pp. 317-368. 
europea de Rebolledo se prolonga hasta 1659, con su permanencia en la corte danesa, todo ello en el contexto de las convulsiones que sacuden al continente mientras el imperio sanciona su desmoronamiento. Los conflictos religiosos, la Guerra de los Treinta Años y las negociaciones que culminan en la Paz de Westfalia, con todas sus consecuencias, son el escenario de una verdadera peregrinación para el conde, y funcionan como trasfondo de su cada vez más acentuada sensación de desarraigo ${ }^{6}$. La enajenación de su suelo patrio se exacerba durante la permanencia en las tierras del norte, y no sólo por el cansancio y lo precario de su salud. Son éstas unas tierras más reales que las cruzadas por los peregrinos del Persiles; de ellas mantienen sus dosis de misterio y fondo legendario, que las convierten en espacio de la maravilla, pero suman algo de ominoso desde la experiencia directa que raya en el aislamiento, pues el poeta no encuentra la compañía necesaria para alcanzar ese mínimo de seguridad encontrada por los miembros del grupo de la póstuma novela cervantina. La situación política tampoco contribuía precisamente a consolidar una posición estable, una sensación de orden. En tensión con tan honda experiencia personal (individual y colectiva), el diplomático busca ordenar su obra poética ${ }^{7}$ en una suerte de itinerario virgiliano, desde la sencillez

6 Una reciente aproximación a las circunstancias y el perfil de nuestro autor es la de Ana Isabel Martín Puya, "Periferias de un noble: el conde de Rebolledo", en Heterodoxias y Periferias: La Poesía Hispánica en el Bajo Barroco, ed. Itzíar López Guil, Adrián J. Sáez, Antonio Sánchez Jiménez y Pedro Ruiz Pérez, monográfico de Versants. Revista Suiza de Literaturas Románicas, LX, 3 (2013), pp. 119-129. En el mismo volumen pueden encontrarse consideraciones sobre poetas coetáneos en similares posiciones, como las que apunta Antonio Sánchez Jiménez, "El converso y los bucaneros: Miguel de Barrios y Piratas de la América (1681)”, op. cit., pp. 162-163, a propósito de Miguel de Barrios: "las ambiciones poéticas de un poeta doblemente relegado a la periferia le impulsaron a adoptar una estrategia de emulación y búsqueda de autoridad. Este objetivo llevó a Barrios de la poesía a la ciencia y a la tecnología cartográfica, en búsqueda de un elemento diferenciador con el que exornar su texto y con el que proseguir de modo original el camino iniciado por Góngora”; como veremos, la relación entre esta posición y la de Rebolledo es destacable.

7 Una completa noticia de su producción puede encontrarse en Rafael González Cañal, "Rebolledo, Bernardino de, conde de», en Diccionario filológico de literatura española. Siglo XVII. Vol. 1, dir. P. Jauralde Pou, Madrid, Castalia, 2010, pp. 248-252. 
de la lírica en los Ocios (1650) y el carácter didáctico-doctrinal de la Selva militar y política (1652), complementado en la vertiente religiosa por los ensayos genéricos sobre materia veterotestamentaria (la versión de los salmos -odas- en la Selva sagrada, de 1657; el diálogo dramático en que traslada la historia de Job, en La constancia gloriosa, de 1655; y la versión elegiaca de los lamentos de Jeremías, en Los trenos, aparecidos entre las Rimas sacras, de 1660) y la narración del Idilio sacro (1660), más bien un epilio sobre la vida de Jesucristo. La persistencia en el uso de la silva en todos estos textos apunta una cohesión orgánica, acentuada en la agrupación editorial de todos sus textos en una suerte de "obras poéticas completas", aparecidas en la Oficina Plantiniana de Amberes, entre 1660 y 1662, culminando un camino de impresiones por distintos puntos de Europa (Múnich, Colonia, Copenhague...). Esta empresa constituye toda una "rúbrica de poeta" para materializar una clara conciencia autorial, individualizada en su particular mezcla de lo humano y lo sacro, con la cohesión de una sentimentalidad que se mueve entre el lamento y una tímida celebración, y que asciende en ello por los grados de la vivencia amorosa, la experiencia militar y política y una cierta mirada desde el final del camino, representada precisamente por las Selvas dánicas (Copenhague, 1655), la última y más elevada (por materia y, sobre todo, por sublimis stilus) de sus obras profanas. En este texto se condensa la experiencia de las "tierras del norte", y desde ella el autor da una vuelta de tuerca a su situación, entre lo literario y lo vital, una torsión a una determinada visión de la selva, con la que pretende concertar la historia y el mito, la naturaleza y el artificio, todo ello bajo el signo de la maravilla.

En la composición, también en la habitual combinación libre de endecasílabos y heptasílabos siguiendo el modelo gongorino, ya no es el bosque o la selva lo que fija la admirada visión del poeta y su admirable palabra. Se trata de algo más cercano a su entorno, a su posición como diplomático en el extranjero: la estirpe regia y el palacio de la soberana danesa, Sofía Amelia de Brunswick-Lüneburg. Con su retrato en los preliminares, en posición que solía ocupar el del propio poeta, la reina es la dedicataria de la obra y en una parte sustancial también la destinataria privilegiada de la misma, en gran medida como parte del juego de acercamientos y alianzas de la función diplomática del poeta. De manera más directa y con más perceptible trabazón con la materia argumental del 
poema, hay también un motivo de correspondencia, ya que Sofía Amelia le había cedido a Rebolledo su palacio de Hersholme, para que descansara y aliviara sus penas de desterrado. Junto al medallón con el busto de la reina Rebolledo incluye un poema en el que se mezcla la celebración de la dama y, a través del pintor-grabador, una reflexión sobre su papel como artista, es decir, como emulador de una realidad en la que no faltan los componentes míticos:

\section{Al artifice del retrato}

¿Cómo el arte pudiera copiar los ojos que no ve a Cupido, ni reducir las lumbres de la Esfera a lienzo desigualmente teñido? Que no se dan celestes esplendores a la prisión de frágiles colores; del humano sentido lo material tal vez se dificulta; en piélagos de luz el Sol se oculta y la Beldad que más con él compite a menos atenciones se permite. ¡Oh, cuán en vano suda tu porfía en formar el retrato de sofía, suprema majestad, deidad humana, que si la juzga Venus es Dïana, y si a Diana retratar procura ofenderá a Venus la hermosura! ${ }^{8}$

Las referencias metapoéticas apoyadas en la imagen de la pintura (arte, copiar, reducir, lumbres, lienzo teñido, prisión de frágiles colores, lo material, la Beldad, el retrato) confluyen en la actualización del tópico de la comparación mitológica, para exaltar la belleza de la dama (Venus) y unos atributos identificables con los de Diana, casta y cazadora. Si la imagen de la caza tendrá amplia recurrencia en la dedicatoria y en el cuerpo del poe-

8 Tomo el texto de las Selvas Dánicas del conde Rebolledo, señor de Irián. En Coppenhagen, impreso por Pedro Morsingio, impresor regio y académico, año 1655. Modernizo grafía y puntuación. 
ma, en su segunda parte, también introduce una paronomasia con Dania, el país de que va a tratar el poema, mientras que su núcleo espacial, el palacio de Hersholme aparece como centro de la actividad cinegética. Además de lo trabado de la composición, este breve epigrama, en el que la brevedad de la silva toca con el madrigal, apunta las intenciones autoriales. En sus Selvas, Rebolledo convierte el agradecimiento en panegírico personal y de linaje (adelantados en el retrato y en la identificación de la dama con su reino), y éste en una experiencia estética (infra), partiendo de la cronografía y la topografía, para desplazarse de lo real a lo exótico, del topos al $u$-topos, teńidos siempre de la maravilla propia de la mirada de un peregrino, de un extranjero. El diplomático vive una sensación de exilio, de extrañamiento respecto a la patria, pero también se siente forastero en tierra ajena. Es una forma doble de alienación. Con ella la mirada se focaliza por desubicación del punto de vista, de la atalaya de la observación, con el consiguiente efecto en la mirada y su repercusión en la naturaleza de la visión, que se hace peregrina.

Siguiendo el modelo de las Soledades gongorinas, aunque doblándolas en número de versos, el poema-libro se articula, tras los preliminares, en una dedicatoria y dos silvas ${ }^{9}$. La primera reproduce muchos de los tópicos desplegados en este elemento por el cordobés, con la presencia del peregrino que asumirá la función de foco de la mirada, las ocupaciones guerreras o políticas habituales en el aristócrata, sus momentos de ocio, dedicados a la caza, la petición de que se detenga a escuchar, la promesa de la fama y otros loci menores. Más allá de su estricto papel retórico en la inicial captatio benevolentiae, la evidencia de su diseño retórico plantea en la apertura del poema, desde el magisterio del cordobés, la altura de las pretensiones del escritor, a la hora de dignificar el presente ofrecido a la princesa, pero también a la hora de codificar su presentación de la ma-

9 Aunque en forma más remota, también se transparenta algo de los planteamientos presentes en el Panegírico al duque de Lerma, donde Góngora, en este caso en una métrica y una estructura retórica más clásica, aborda la empresa de alcanzar la sublimidad estilística a partir de la elevación de la materia, con la exaltación del valido. Del modelo genérico pudieron tomar tanto Góngora como Rebolledo los procedimientos de inclusión de la celebración del linaje y de las posesiones del dedicatario. Retomo más abajo el sentido de la dedicatoria y las relaciones simbólicas con la protectora o mecenas. 
teria. No es sólo la elocutio lo que emparenta las Selvas con las Soledades, sino de un modo aún más trascendente la focalización de su discurso, encomendado a una mirada que busca la maravilla desde su posición exterior, con la distancia de una visión que opera desde la alteridad y desde ella traslada a los versos su condición admirativa.

La primera silva, L’Aula, es una larga y panegírica relación de los antepasados de Sofía Amelia, sus predecesores en el trono, ahondando las raíces de Dania hasta su solar mítico, en los tiempos primordiales. Se presenta a modo de una genealogía, con mucho de la reiteración estructural aprendida en los libros del Antiguo Testamento, a los que en estos mismos ańos está volviendo para tomar su materia poética. Como en el inicio de Números y Jueces, o en el libro I de Paralipómenos, Rebolledo se extiende en una prolija genealogía, enlazando antecesores y sucesores en una cadena reiterada, sancionada en su misma continuidad, que convierte su sintagmático devenir en una suerte de espiral que sólo se libra del eterno retorno por su avance, como destino inexorable, hasta el presente de quien ha recibido una herencia y ha coronado una dinastía. Cuando el devenir del tiempo se presenta al modo de una reiteración, se inclina de forma imperceptible al ámbito del mito, de una leyenda a la que el poeta accede a través de un ejercicio de erudición, posiblemente buceando en los textos de Olao Magno y Saxo Gramático, que, si bien no se encontraban entre los registros conocidos de su biblioteca, fueron citados por el autor ya desde los versos de los Ocios ${ }^{10}$. Siguiendo el linaje de gobernantes, Rebolledo tiende un puente entre el pasado legendario, las raíces míticas, y el presente, al que el lector accede ya con la suspensión de la maravilla, preparado para acceder con los ojos de la admiración al espacio que se le va a describir. Tal es la función que, añadida a la del topos de la alabanza, cumple esta silva inicial, L'Aula, antesala a la pintura no menos celebrativa en la segunda parte de la obra. La explotación de la etimología de la voz usada como rótulo le sirve al autor para potenciar esta función. Los diccionarios de principios de siglo dan cuenta del uso y sentido del término al modo habitual en nuestros días. Así, Palet (1604),

10 El inventario de los libros que en un momento poseyó el aristócrata es recogido, identificado y analizado por $\mathrm{M}^{\mathrm{a}}$ Concepción Casado Lobato, "La biblioteca de un escritor del siglo XVII: Bernardino de Rebolledo", Revista de Filología Española, LVI (1973), pp. 229-328. 
Oudin (1607) y Vittori (1609) apuntan el significado de marco de la enseñanza ("sale où l’on fait la leçon" o "sala di publico lettore"). En nuestras letras, Covarrubias ofrece una semántica más amplia cuando registra la voz: "propiamente sinifica el lugar cercado, espacioso y desahogado, y porque delante de las casas de los reyes y grandes señores ay estas plaças y parques, que podemos llamar patios de palacio, los mesmos palacios se llamaron aulas y los cortesanos áulicos"; sólo en un pasaje posterior señala el uso docente y explica el desplazamiento al mismo. El Diccionario de Autoridades (1726) abunda en los sentidos que Rebolledo explota en su denominación, pues los lexicógrafos de la Academia señalan que se trata de "la corte y palacio real de los príncipes y soberanos. Es voz griega AULA, que en su propio significado corresponde a lo mismo que atrio o lugar ancho y cercado". La parte inicial de la composición, en la que no nos vamos a detener en este momento, muestra de esta forma su carácter casi ancilar, de preámbulo o atrio a lo que va a constituir el verdadero centro, no de simetría, de sentido de toda la obra, apreciable entre sus rasgos de "selva".

El preámbulo genealógico e histórico lleva al lector a la segunda de las silvas, Hersholme, ahora sí el nombre propio del palacio, el lugar de reposo del poeta y pabellón de caza de la reina, centro de una descripción ecfrástica, alargada hasta las dimensiones de la alegoría, esa forma de la trascendencia barroca. La sintagmática sucesión en el tiempo de monarcas daneses, extraída de las lecturas, deja paso ahora a una dimensión puramente espacial, convertida en paradigma, donde el tiempo se detiene, y su estructura se ordena en un orden muy diferente al lineal. La noción de una silva ecfrástica nos trae a la mente la muy cercana obra de Soto de Rojas, el Paraíso cerrado para muchos, jardines abiertos para pocos (1652), otra de las proyecciones señeras del modelo de las Soledades. A diferencia de la propuesta del cordobés, Rebolledo coincide con el granadino al separarse de la visión poética de la naturaleza para acercarse a la descripción de una construcción humana, pero que recompone y reconecta lo mítico, entre el paraíso y el palacio de las maravillas, desde las Kunstkammeren ${ }^{11}$

11 Las cámaras o gabinetes de maravillas trascendieron los límites de las primeras colecciones humanistas de piezas artísticas y se erigieron en verdaderos emblemas barrocos. En estrecha cercanía a Rebolledo y su obra, es interesante recordar la iniciativa del médico y anticuario danés Ole Worm y su Kunstkammer, creada en 
al también cercano espacio de "Los prodigios de Salastano", dibujado por Gracián en la segunda parte de El Criticón (1653). El palacio aparece en los versos del conde como cristalización de la secuencia, casi extática en la repetición, de la silva anterior. En ellos la naturaleza no se ordena en el jardín, sino que se sublima a través de las representaciones plásticas, desplegadas en una variedad de formas y técnicas recurrentes a lo largo de esta segunda parte. Protagonismo especial tienen los lienzos de Van Mander, pero también los frescos de la bóveda o la galería de retratos regios, como eco de la relación previa y enlace entre las dos mitades de la composición, sustentando la idea de que el palacio de Sofía Amelia condensa en lo material el legado de una estirpe, da cuerpo en sus estancias y su contenido a una gloria desplegada en el tiempo, convirtiendo, como el arte, la historia en memoria. Esa función cumplen los distintos géneros pictóricos, y a ellos se suman las representaciones de escenas de caza, ya evocadas en la inicial referencia a Diana y en la significativa dedicatoria ${ }^{12}$. Los pasos del peregrino conducen al lector a través de esta verdadera pinacoteca del palacio hasta que unos y otro desembocan en un mapa del reino, pintura a escala de la realidad y verdadera mise en abyme casi borgiana, pues la fijación cartográfica, espejo reductor, vuelve a poner en tensión las relaciones entre la realidad y su representación, sustituyendo la primera por la segunda, de la misma manera que el poema representa la realidad y el mapa, conteniendo a ambos en un juego de reflejos especulares, uno de los elementos habituales en las Wunderkammeren. A través de los ojos de

Copenhague en 1654. En su faceta de naturalista, Worm se movió en los albores de la ciencia moderna, aunque sin romper del todo con la vieja formulación. En el póstumo Museum Wormianum (1655) se recogieron grabados de su colección y distintas observaciones sobre sus piezas.

$12 \mathrm{Ha}$ actualizado muy recientemente la presencia de la materia cinegética en las dedicatorias, de Virgilio a Góngora, Roland Béhar, "Tu mibi: variaciones bucólicas sobre un ritual de dedicatoria, de Virgilio a Góngora”, Nueva Revista de Filología Hispánica, LXI (2013), pp. 65-98. De manera más específica, Pedro Ruiz Pérez, "Garcilaso y Góngora: las dedicatorias insertas y las puertas del texto", en Paratextos en la literatura española. Siglos XV-XVII, ed. Ma Soledad Arredondo, Pierre Civil y Michel Moner, Madrid, Casa de Velázquez, 2009, pp. 49-69. En el otro extremo de la composición gongorina se sitúa la escena cetrera, estudiada por Jesús Ponce Cárdenas (infra), quien también está dedicando trabajos en marcha a la pintura de Van Mander. 
la maravilla lo que emerge es el arte, el de la pintura y, sobre todo, el del verso, del que el mapa es una metáfora, ya que en ambos se encierra un espacio que cabe recorrer con los pasos o con la lectura.

Cobra aquí sentido lo apuntado respecto al poema inicial, que acompaña (otra representación) el retrato de la reina, grabado sobre un óleo de autor desconocido y fechado c. 1650. La alabanza del autor del retrato funciona como celebración del arte del poeta, plasmado a través de metáforas de luz y de mirada (ojos de Cupido, las lumbres de la esfera, los celestes resplandores, los piélagos de luz). Aun sin una consideración demorada en las raíces platónicas, tanto en la dimensión epistemológica como en la estética, podemos ver en estas imágenes la voluntad de apresar y expresar la maravilla, de acceso poético a una dimensión arcana, a la que alude la apelación de "novello Orfeo apresso Clio" que el autor recibe en otro de los poemas preliminares, el soneto "Per la primera Selva dánica", de Scipione Mariotti, secretario del consorte de la reina, el duque Federico. La evocación de la musa de la Historia se justifica por la referencia a la primera parte de la composición, pero la imagen de quien penetró en territorios recónditos y ajenos a lo humano y supo cantar su experiencia y su visión puede extenderse al papel del autor en el conjunto de la obra. Así, con esa dialéctica entre lo visto y la visión, entre la mirada y la palabra, entre la naturaleza y el arte se despliegan las silvas en un camino hacia el interior, el del palacio y el de la naturaleza de las cosas.

\section{Teatro de signos}

Entre los meandros de silva y selva, ajenas a la lógica ordenación de las octavas y los jardines, discurre una mirada desde la que se ofrece la pintura de una geometría, de una cartografía, entre simbólica y onírica. La atención a los detalles de sus componentes se ve ratificada y acentuada al contemplar el mapa trazado y la dirección del itinerario. En su intersección comprobamos que el universo recompuesto en la silva Hersholme se articula, siguiendo sus espacios con el recorrido de la mirada, en un proceso de ahondamiento, de adentramiento hacia la cripta. El texto ordena el espacio en una serie de círculos concéntricos, que el peregrino recorre como el personaje dantesco, con la misma sensación de maravilla. En el 
más externo se sitúa Dinamarca, caracterizada como "devota”, en clave de posicionamiento en las abiertas guerras religiosas del momento, partiendo así de un inequívoco elemento de historicidad y de realidad geográficoespacial. Con algo de desplazamiento metonímico, peregrino y foco narrativo desembocan en un lago, cuyo epíteto es "cristalino", iniciando una aproximación a una versión actualizada y barroca, mucho más artificial, del locus amoenus clásico y renacentista. En el centro del lago se descubre un "isleo", cuya adjetivación, "ameno", confirma la introducción en el topos, en el que se combina geografía literaria y percepción de lo real. Entre una incipiente estética del gusto y una revisión de la poética clasicista por el embate coincidente de la complejidad intelectual del manierismo y la demanda de un público heterogéneo ante la creciente mercantilización de los textos en las prensas y en los tablados, lo ameno remite en estos momentos a un componente de variedad, igualmente propio de las selvas reales y de las silvas poéticas, y ampliamente plasmado a lo largo del recorrido de pasos y versos. La identificación de los componentes de esta variada amenidad con elementos de la tópica consagrada remite al lector a los escenarios conocidos, sobre todo, en la narrativa idealista, entre la caballeresca y la bizantina. Incluso el soslayo de la forma habitual de "isla" nos remite al universo de "ínsulas extrañas" que, desde las páginas de los Amadises, llega incluso a las liras sanjuanistas, con amplio despliegue en relatos del tipo del plasmado por Núnez de Reinoso en Los amores de Clareo y Florisea, publicada un año antes en los comienzos de un género con una marcada revitalización en la primera mitad del siglo XVII, incluyendo, desde Cervantes, un interés por las "tierras del norte" y su aura de misterio. La maravilla, en cambio, no aparece en la silva de Rebolledo en forma de castillos encantados o figuras monstruosas, como las ofrecidas a los caballeros; antes bien, en medio del "isleo" se levanta otra forma de construcción humana, ligada estrechamente al arte.

Al penetrar en la isla, el peregrino se encuentra en medio de un "teatro", al que accede con "pasos dudosos en no conocido laberinto", tras un "extraño enredo"; vencidas las dificultades, el lector le acompaña al descubrimiento de un "retrato del paraíso". Las consonancias con el hipotexto gongorino evocan un mundo de soledades, de espacios de retiro y contemplación, pero también de extrañamiento y de confusión. La imagen del dédalo, más allá de toda su carga simbólica barroca, arrastra 
las connotadoras referencias al monstruoso hijo del pecado, a la artificiosa construcción para su clausura y ocultamiento y al hilo de Ariadna necesario para abrirse paso entre la confusión y acceder al misterio de Asterión y su condición biforme, animal y humana, cuerpo y alma, naturaleza y artificio. La imagen de confusión se extiende a todos los elementos, contaminando, desde lo laberíntico del camino, la percepción del peregrino y la condición de lo que se abre ante su mirada, incluso cuando el enredo parece deshacerse y los pasos concluyen su camino. Lo que se abre en este punto es un "teatro", cuyo primer sentido es el etimológico, tal como lo recoge Covarrubias, al relacionarlo con el verbo griego "theomai", 'ver'; así, el teatro es originalmente un lugar para la exposición de algún objeto, generalmente en una disposición heteróclita, de colección miscelánea ${ }^{13}$ propuesta para su contemplación, esto es, dada en espectáculo, de donde el sentido se desplaza y se especializa como lugar de la representación escénica. Este marco es el que se le ofrece al peregrino y a su lector, pero sin que en la presentación se soslaye del todo lo que tiene de representación, y no sólo en su transcripción verbal. Si no con el sentido de ficción o de engańo a los ojos, la noción de "teatro" mantiene el valor de algo figurado, como el reflejo de un espejo. La noción de "retrato del paraíso" concreta y verbaliza este valor, ya que a lo que se accede no es directamente al paraíso, sino a lo más cercano que se puede estar de él en este mundo, a su retrato, esto es, a su representación. Estamos ante un simulacro, ante una imitación por la vía del artificio, de lo que constituye el objeto de la contemplación, de retiro o del peregrinaje. Ahora el abandono del tráfago urbano no lleva directamente a la naturaleza, sino a su representación, pues sólo desde ella es posible acercarse al sueño del paraíso. El marco presentado por Rebolledo no podía ser más adecuado: la isla es imagen de la alteridad, de la salida (del yo, del marco social, de la normalidad), espacio propicio para la maravilla, al tiempo que símbolo de la intimidad, de un inconsciente viaje interior hacia lo profundo ${ }^{14}$, en un sentido intui-

13 Así aparece en diversos títulos, de Lugo y Dávila en su colección de novelitas cortesanas (Teatro popular, 1622) a Feijoo y su recopilación de ensayos (Teatro crítico universal, 1726-1740), sin ninguna relación con la acción dramática ni la puesta en escena.

14 Véase lo apuntado por Mario Tomé, La isla: utopía, inconsciente y aventura. Hermenéutica simbólica de un tema literario, León, Universidad de León, 1987. 
do ya por Covarrubias y que apunta a la suspensión, como la producida por la admiración: "Aislarse uno es cortarse y pasmarse sin discurrir en ninguna cosa. Quedarse aislado, quedar pasmado"; si en Juan de la Cruz las ínsulas extrañas pueden relacionarse con el éxtasis, con el abandono místico, el sentido es algo más profano en las Selvas dánicas, pero igualmente relacionado con el sentido del estupor, de la suspensión. El teatro localizado en el centro del isleo concreta la maravilla en el espacio del artificio y la representación.

En el centro del teatro se erige el palacio. Su arquitectura triangular introduce un llamativo punto de contraste con la geometría concéntrica del espacio hasta ahora descrito, como marcando la diferencia en el paso de lo natural a lo artístico, de un orden de raíces cosmogónicas a una distribución espacial acomodada a los propósitos humanos. En cada uno de los tres cuerpos de la construcción se sitúan las escenas pintadas a las que ya nos hemos referido, y en su descripción descubrimos toda su potencialidad significativa: al valor simbólico de sus referentes se ańade, con efecto multiplicador, la propia condición de su referencialidad, desarrollada por la écfrasis, donde el verso es el último extremo de una cadena con inicio en la imagen mítica y desarrollo a través de sus formulaciones plásticas, las que sirven como modelo a la descripción poética. Su mismo orden revela la trascendencia simbólica de estos signos de signos. En primer lugar nos encontramos con los lienzos, con la conocida firma de Van Mander, reunidos en la figuración de escenas de caza, a través de las cuales se pone en comunicación la realidad, la de la práctica cinegética a la que se destinaba el palacio de Hersholme, con el mito, el de la Diana que preside todas las imágenes proporcionadas por la mitografía; entre ambas orillas, la conexión de la diosa con la princesa dedicataria retoma la ya presentada explícitamente en la inicial identificación del poema con el retrato y en las referencias a la caza en la misma dedicatoria; al reaparecer en el núcleo del poema, establece un espacio simbólico, un lugar de representación en la frontera de la trascendencia, de la maravilla. Todas las figuras (Atalanta, Acteón, Orión, Endimión) aparecen en relación directa con Diana, pero revelando la complejidad de su imagen, lo multifacético del mito, donde se encierran muchos de los elementos del misterio: la noche y la luna, la caza, lo prohibido, la castidad y el amor, la metamorfosis y el sueño, lo femenino... Los diferentes finales (la unión, la muerte, el catasterismo) 
acceden por vías complementarias a la admiratio, en estrecha relación con lo dramático de las relaciones entre los humanos y la divinidad, con el amor como fuerza irresistible y tan próxima a la sublimación como al aniquilamiento.

Por esta vía conectan los lienzos con los frescos contemplados en la bóveda del palacio, que, como en los plasmados por Pacheco en la de la sevillana Casa de Pilatos, se centran en el motivo de la caída, con personajes convertidos en espejos de príncipes, en particular en un momento en que la política cristiana y la razón de estado seńalaban la prudencia como el principal valor del gobernante ${ }^{15}$. Faetón e Ícaro ya venían cumpliendo en las décadas precedentes este papel, por igual en poesía y pintura, con la emblemática como privilegiado punto de intersección de las dos artes. En el contexto del poema la inclusión en un tríptico de la figura de Dédalo, constructor de artificios, vuelve a actualizar la imagen del laberinto, poniendo en relación confusión y caída, sobre el motivo de la desorientación, pero también el del arcano. De otro lado se encuentra, ahora en un nivel inferior y en un recorrido lineal, la galería de retratos regios; su eco de la silva inicial se multiplica en el plano de la referencialidad extratextual, con la aparición en la serie de la representación de Sofía Amelia, otra vez en el lienzo con los atributos de Diana, en una exaltación propia del panegírico y, a la vez, estrechamente vinculada a la estructura epistemológica de una mirada empeńada en indagar en la trascendencia y encontrar tras la apariencia de lo real la condición de lo arquetípico, de lo mítico, eso sí, a través de la representación artística.

El procedimiento se observa con claridad al pasar a la otra ala del palacio y sus representaciones plásticas, de nuevo lienzos, como las presentadas inicialmente. De manera destacada, un episodio de cetrería nos devuelve a las Soledades y su misteriosa y abierta conclusión ${ }^{16}$, mientras

15 Así lo recoge el propio Rebolledo en su Selva militar y política (1652), apoyado en la amplia bibliografía sobre la materia, como la que poseía en su propia biblioteca. Me acerco a algunos aspectos de este texto en "Imágenes políticas en la Selva de Rebolledo", en Politica y literatura en el Siglo de Oro, coord. Jorge García López, monográfico de Studia Aurea (2014).

16 Para seguir la proyección de este episodio resulta muy útil el estudio de Jesús Ponce Cárdenas, "La imitación del discurso gongorino de la cetrería: primeras calas", en Los géneros poéticos del Siglo de Oro: Centros y periferias, ed. Rodrigo Cacho Casal y Anne Holloway, Woodbridge, Tamesis, 2013, pp. 171-194. También me acerqué al 
conecta con la materia previa, la de la caza, la del vuelo, la de la ocupación de los príncipes. Lo significativo ahora es su marco, pues la escena cinegética se sitúa entre distintas representaciones de las estaciones del año. Se trata también de cuadros de género, con bastantes modelos, en particular en los "lienzos de Flandes", y con lógica tendencia a agruparse en series. Al margen de su indiscutible valor decorativo y su previsible presencia en los muros de un palacio de la Europa septentrional, el género nos remite a una concepción cíclica, que ofrece a la vez la metamorfosis de la naturaleza derivada del fluir del tiempo y la permanencia esencial bajo el cambio. La concepción cíclica, sugerida en la inalterable sucesión de monarcas daneses, y propia de la temporalidad esencial del mito, aflora de nuevo en esta naturaleza filtrada por la mirada y el pincel del artista. En sus representaciones los ciclos estacionales apuntan una conexión entre la inmediatez del espacio natural y las revoluciones de las esferas celestes, entre lo inmediato y lo elevado ${ }^{17}$, y su apertura al espacio de lo simbólico se hace operativa con la introducción del último juego de la maravilla, la clave de bóveda de este edificio de espejos enfrentados. Se trata de la representación, en medio de esas pinturas, del propio espacio que las contiene, la isla y el palacio de Hersholme, que en este momento el lector espańol conoce que significa “isla de los ciervos”, multiplicando la tensión de este complejo microcosmos artístico, donde palacio, cuadro y poema borran sus fronteras en un juego de imágenes donde quedan problematizadas las relaciones entre realidad y ficción, entre naturaleza y arte, creando un nuevo espacio para la maravilla.

Como consciente de este efecto, el poeta hace desembocar el recorrido de peregrino y poema en un nuevo espacio de representación, aunque en este caso más cercano a la racionalidad del logos, de la palabra. Pasos y versos en su camino hacia el centro concluyen en la biblioteca. Su aparición, como en El Criticón, no podía faltar en un recorrido por los espacios de la maravilla, pero en los versos de Rebolledo, con la simetría estable-

asunto a propósito de un extenso pasaje del Poema heroico del Gran Capitán: "Una proyección de las Soledades en un poema inédito de Trillo y Figueroa”, Criticón, 65 (1995), pp. 101-177.

17 Apunto más abajo la relación de estos aspectos al hilo del comentario sobre la teoría copernicana que Rebolledo incluye en los versos que se citan. 
cida por el hecho de la pertenencia de espacio y libros a la dedicataria, adquiere una dimensión especial tal como la registró Roger Chartier:

[...] el rey se convierte en poeta o en sabio, y su biblioteca no es solamente un tesoro que preserva riquezas amenazadas, o una colección útil para el público, o incluso un recurso de placeres privados. Se transforma en un espejo en el que se refleja el poder absoluto del príncipe $^{18}$;

y ha glosado Roland Béhar, centrándose más en la dedicatoria:

La dedicatoria se convierte en el lugar de la expresión poética del patronazgo, en tanto que éste crea el espacio y el ocio necesarios para el estro del poeta. Inserta en la misma economía del texto poético la imagen de la instancia que le permite existir. Representa, además, la función del texto que no consiste sólo en divertir honestamente a un ingenio capaz de disfrutar de la poesía, sino también en transfigurar la misma realidad a la que pertenece y conferirle el brillo propio de una existencia donde los dioses se mezclan en la vida de los hombres ${ }^{19}$.

También en la librería del palacio regio estamos ante un mundo de ilusión, con la ficción de la poesía; no obstante, en esta librería figurada, como en la poseída realmente por Rebolledo, la imaginación literaria convive con los textos científicos, empeñados en estos años, los de la "ciencia nueva", en la elucidación, comprensión y dominio del reino de la naturaleza. Si el poema no se detiene tanto en estos asuntos, sí apunta dos elementos de sustancial importancia en la interpretación del texto, desde la condición de lo narrado a su lectura en clave moral. El primer aspecto aparece cuando se insinúa la condición onírica de la experiencia, que explicaría la maravilla del recorrido y aun su misma estructura, con el confuso deambular de los sueńos y la potencia de sus imágenes. La modernidad del recurso, uno de los fundamentales en el asentamiento del estatuto de la ficción, interesa ahora menos que su eficacia para justificar la inclusión de la maravilla e incluso para dirigirla a una de sus funciones

18 Roger Chartier, "Poder y escritura: el príncipe, la biblioteca y la dedicatoria (siglos XV-XVIII)", Manuscrits. Revista d'Història Moderna, 14 (1996), pp. (p. 212).

19 Roland Béhar, op. cit., p. 96. 
más aceptadas, que lleva de la fábula a la aplicación moral, aun cuando se trate de algo más ligado al plano de la experiencia individual que al de unas reglas de carácter doctrinal y valor didáctico. Esta dimensión es la que viene introducida por las referencias a un contenido destacado de la biblioteca, el de los autores de moral estoica.

El motivo tiene una primera aparición no libresca, en la experiencia del peregrino y su viaje de valor simbólico e iniciático. En medio del camino se registra el encuentro con el anciano agricultor, en una actualización del tópico que jalonará, por ejemplo, las distintas crisis de la obra graciana, en tanto evoca de manera más directa el episodio de las Soledades. Como en todos los casos señalados, la coincidencia de los personajes se resuelve en texto, en este caso con el intercambio de relatos autobiográficos. En su discurso se pasa de la dimensión del pathos (la vida y sus sentimientos, con el padecimiento ligado a la situación de exilio, iniciado en el pasado) a la del ethos (la de los valores susceptibles de convertirse en guía para los comportamientos futuros). Más aún que los libros, la vida, con la lección de la experiencia y de los viajes, puede adquirir la condición de ejemplo, de modelo, identificado, a la manera estoica, con un tono de medianía y, sobre todo, con un ánimo constante, que remite al ideal neoestoico forjado para el XVII a partir de las doctrinas de Justo Lipsio. Más allá de la formulación barroca, cruzada de elementos de senequismo y moralidad cristiana, la original doctrina de la Stoa se presenta como una ética particular, pero también como una epistemología, que arranca con una mayor atención y credibilidad a la naturaleza que a la ortodoxia doctrinal, a la observación de lo concreto e inmediato por encima de las leyes de presunta aplicación general. Un fragmento de la confesión sobre sus ocupaciones y actitudes por parte del anciano, elevado a la condición ideal de sabio en su retiro, ilustra lo apuntado ${ }^{20}$ :

Y en este sitio, por favor del dueño,

la gozo dulce y apaciblemente,

sin que me quite el sueño

ningún adverso o próspero accidente,

20 Conde de Rebolledo, Selvas Dánicas, ed. cit., pp. 94-99. A falta de una edición moderna, numero los versos desde el inicio del pasaje a efectos exclusivos de facilitar su localización en este trabajo. 
contento con la suerte

de ni temer ni desear la muerte.

Al despertar el alba aquí me llaman

esos sonoros órganos de pluma,

y en bóvedas frondosas

de que son estos árboles colunas

que nos forman capillas no indecentes

a Dios damos loores

en coros diferentes,

del Céfiro templado entre las ramas

en los labrados mármoles las fuentes,

y yo con los sonoros ruiseñores,

y le ofrecen fragantes sacrificios

de perfumes las flores

por los inexplicables beneficios

de aquella Providencia

a que debemos ser y consistencia,

y de las calidades la materia y forma;

de elementos o puros o alterados, mistos inanimados,

plantas, árboles, frutos y simientes,

aves, peces, reptiles animales,

hago especulaciones diferentes

$y$ tal vez experiencia,

sin reducirla inútilmente a ciencia

ni examinar con pérdida de tiempo

si de las continuadas cantidades

la división en partes

ha de ser infinita

como quiere el sutil Estagirita,

o, cual Zenón, en puntos de límite infalible,

cada uno en sí mismo indivisible;

ni se podrán juntar sus unidades,

las que quiere Epicuro inanidades,

teniendo por doctrina más constante

lo indivisible del presente instante.

Espero que vendrá la primavera

de pámpanos y flores coronada,

de mieses el verano, 
el otoño de fruta sazonada, y el invierno de hielo y nieve cano,

y con leve mudanza

rara vez me ha engańado la esperanza.

Investigo las causas

de esta infalible variedad de efectos,

los impulsos violentos

de los feroces y contrarios vientos,

del vapor que de tierra y agua sube

a convertirse en nube

y con tema inoportuna

invidioso porfía

quitar el sol al día

y a la noche la luna;

exhalación veloz el aire dora,

encendido cometa

las púrpuras reales descolora,

rayo los sacros templos no respeta

y con ardiente guerra

las más excelsas máquinas atierra,

y en nieve y en granizo congelado

o lluvia desatado,

de su misma materia combatido, vuelve a morir a donde había nacido.

Por la región diáfana navego,

los orbes inquiriendo a la celeste,

sin que me lo embarace la del fuego,

incendio fabuloso

que, con celo ambicioso

de oponerse a Platón osadamente,

sin razón concluyente

al de la zona tórrida añadía

vana filosofía;

este y aquel en siglo más curioso,

con mejor atención examinados,

deben ser igualmente refutados.

Penetrables sus círculos supone,

contra diversas sectas,

el haber visto en parte 
superior al de Marte

impresiones de fúlgidos cometas,

de que no pocas nos dejó señales

Séneca en las Cuestiones naturales.

Del sol, la luna y los demás planetas

observo alguna vez los movimientos,

sin dejarme vencer al de la Tierra,

sentencia de Platón insinuada

90

pero no confirmada,

puesto que tanto a los modernos mueve;

y de este ángulo breve

con líneas imperfectas

por meridianas corro y paralelos

el ámbito espacioso de los cielos, sin perdonar constelación ni estrella

desde la menos clara a la más bella, y con mayor estudio me prevengo

a conocer lo que más cerca tengo,

y más difícil atención me cuesta

el medir mis pasiones

que del sur a los rígidos Triones,

deseando que el alma

de agitación descanse tan molesta

y en nunca de ellas perturbada calma

con vuelo aspire menos imperfecto,

encumbrándose de uno en otro objeto,

a la contemplación del Soberano,

último fin de todo afecto humano,

cuyo menos o más conocimiento

de la felicidad es argumento.

El pasaje arranca con dos de las más reconocibles fórmulas de la moral estoica, convertidas en los tópicos de prospera et adversa fortuna y nec spe nec metu, actualizados en los vv. 4 y 6 . Su raíz estoica se renueva con una actitud cristiana ligada a la Providencia (vv. 20-22); la referencia a "la materia y forma de las calidades" introduce la actitud de contemplación de la naturaleza, en un conocimiento que se aparta de lo libresco y de lo doctrinal, y se aproxima a un ideal de experiencia, propio de las nuevas 
razones de una filosofía natural que se presenta ajena a los modelos filosóficos heredados, en concreto aquellos fosilizados en una formulación escolástica, la "ciencia" (v. 29) a que no quiere someter las "especulaciones" fruto de la "experiencia" (vv. 28-29) y que parece concretar en las menciones a Aristóteles, Zenón de Elea y Epicuro. Así, con actitud cercana a lo experimental afirma que investiga (v. 48), observando la mudanza de las estaciones en la naturaleza y los fenómenos meteorológicos; en este campo, en actitud más distante de la especulación pitagórica o luisiana, en la "Oda a Salinas", que al telescopio de Galileo, declara: "Por la región diáfana navego, / los orbes inquiriendo a la celeste (...)” (vv. 68-69), aunque al llegar a la teoría copernicana se refugia en una actitud ortodoxa, al margen de la idea cada vez más extendida"1: "Del sol, la luna y los planetas / observo alguna vez los movimientos, / sin dejarme vencer al de la Tierra, / sentencia de Platón insinuada / pero no confirmada, / puesto que tanto a los modernos mueve" (vv. 87-92). La alusión a las Cuestiones morales de Séneca (v. 86) prepara la afirmación con que concluye el pasaje, cuando confiesa: "me prevengo / a conocer lo que más cerca tengo, / y más difícil atención me cuesta / el medir mis pasiones / que del sur a los rígidos Triones" (vv. 99-103). El ejercicio de alcanzar el cielo se mide con el de penetrar en las profundidades del alma, como si adelantara la definición burckhardtiana del renacimiento como descubrimiento del mundo y descubrimiento del hombre, aunque filtrado por el estoicismo, desde el que tratar de comprender la naturaleza y su ordenado discurrir y regir el discurso humano.

\section{LA VISIÓN DEL PEREGRINO}

Conjugando la doble categoría del tiempo y espacio, el quando y el ubi de la retórica clásica, en las dos partes de la obra la teoría o sintagma de los reyes daneses, como queda apuntado, trasciende el devenir temporal, por repetición, y se erige en paradigma, en tanto que el locus paradigmático es recorrido mientras se despliega en sintagma, que traza un programa de ascenso (de accesus al centro) por ascesis y depuración. Al desembocar

21 Se acerca a estos conflictos Elías Trabulse, Ciencia y religión en el siglo XVII, México, El Colegio de México, 1974. 
el recorrido del peregrino en el núcleo del palacio de Hersholme, con su propia representación incluida tras la de las referencias precedentes, el lector alcanza también la relación que se establece entre las dos partes de la obra, al engarzar una cronografía que se mueve entre la historia y la leyenda y una corografía que acaba derivando en una écfrasis. En ella el arte, el del pintor pero también el del poeta, se presenta como una síntesis acabada de ucronía y de utopía, como representación de una maravilla, pues, aunque parta de la realidad histórica o geográfica, opera una mirada que produce la admiración por el acto mismo de la representación, cuando ésta alcanza la necesaria categoría artística. Así quedan perfiladas las dos claves mayores del poema, en estrecha relación: de una parte, la figura del peregrino; de otra, el arte gongorino, cuya obra mayor instaura el arquetipo de nuestro protagonista. En la Selva de Rebolledo volvemos a encontrarnos con el peregrino, pero con algunos cambios significativos en su perfil y su sentido. Tras los pasos confusos e inspirados trazados en la obra del cordobés, quien atraviesa las selvas dánicas trasciende la mera imagen de quien cruza los campos (per-agrum), para encarnar la conciencia del exiliado, la misma que alentaba en su creador. A través de sus ojos se extiende la mirada del expatriado ante lo exótico, lo extranjero, lo extraño, es decir, lo que está fuera y ajeno a él mismo, pero también lo que puede alcanzar la dimensión de lo maravilloso. La enajenación, brotada de la situación de exilio, introduce entre el objeto y el sujeto que lo mira una distancia, que tiende a salvar mediante el lenguaje como instrumento poético, surgido de la admiración, pero también causante del mismo efecto en su lector.

Con las Soledades como filtro e hipotexto, el poema de Rebolledo va de la historia al mito, hasta alcanzar la utopía del palacio de Hersholme como síntesis de las artes y de la mitografía, para acabar en la representación de sí mismo, como objeto suspendido y acabado en su propia imagen. El pasado recorrido en L'Aula, a través de las sucesivas generaciones de reyes, con su dinámica de siglos, desemboca en un presente estático y extático, que alcanza la naturaleza de mito por medio del arte, de la fictio poetica. El palacio es edificado, pero también puede ser pintado y descrito, en una transfiguración propia de la operación artística, metaartística, en este caso, más allá de la retórica figura ecfrástica. Con las Soledades como forma del contenido, las Selvas dánicas se ofrecen a la lectura como 
síntesis de la epistemología barroca y culminación de sus modos expresivos $^{22}$, al límite mismo de sus posibilidades, cuando de un sentido de la maravilla basado en el misterio, en la noción de la trascendencia, se desplaza a la capacidad de desentrańar, ordenar y aun transformar, con una amplia base en la experiencia, cuando no de la experimentación.

La maravillada visión de la naturaleza y de su representación artística (también de su transformación en palacio o su dominio por el gobierno humano) trasciende en los ojos del extranjero que contempla las novedades de Dania el pasmo que la visión de éstas le produce, y lo hace con la voluntariosa orientación de su mirada. Con ella el exiliado, el peregrino, confuso y perdido, puede hallar un punto de inspiración que, como en el encuentro que narra, lo acerca al sabio, con una distancia desde la que puede escrutar lo arcano, lo escondido en los cielos o en el interior de su alma, porque todo verdadero viaje es un viaje interior y porque el conocimiento, como en la epistemología estoica, lleva detrás de sí una ética, una precisa condición humana.

Los alcances de una nueva ciencia, cuyo despuntar se aprecia ya en el horizonte de mediados del siglo XVII, sobre todo en la Europa del norte que vive Rebolledo, podrían inducirnos la tentación de sustituir "inspiración" (la que guía los pasos del peregrino y los versos del poeta) por "ilustración", en la frontera en que la maravilla deja paso a la luz de la razón ${ }^{23}$. Sin embargo, el texto de Rebolledo es, sobre todo, la marca y la manifestación de las tensiones entre dos modelos de conocimiento: una epistemología de base barroca, donde impera el principio de la maravilla, y un atisbo de razón científica y experimental ${ }^{24}$, la que se acerca a la

22 Trata ahora de estos puntos Nicolás M. Vivalda, Del atalaya a los límites del Faetón: narrar la experiencia cognitiva en el barroco hispánico, Potomac, Scripta Humanistica, 2013.

23 Rafael González Cañal, "El conde de Rebolledo y los albores de la Ilustración", Criticón, 103-104 (2008), pp. 69-80, se ha acercado a algunos aspectos de esta dimensión liminar del poeta entre dos épocas. También puede entenderse como indicio de la novedosa actitud, extendida hasta mediados del siglo XVIII, la opción estilística identificada como prosaísmo; véase del mismo investigador "El prosaísmo del conde de Rebolledo", Boletín de la Biblioteca de Menéndez Pelayo, 84 (2008), pp. 169-186.

24 En su estancia danesa, Rebolledo despliega sus contactos diplomáticos con la reina Cristina de Suecia; a ella está dedicada la versión poética del libro de Job, La 
modernidad. Ambas se nos ofrecen combinadas en distintas dosis, en un estado de equilibrio inestable, que sólo puede resolverse en el arte y, en particular, en la poesía, volcando la visión de la maravilla a través de la mirada del modelo gongorino y su andante peregrino, pero actualizados por el tiempo, la distancia y la experiencia vital.

constancia victoriosa (1655), para atraerla al catolicismo y, más determinante aún, a la causa política y militar del Imperio; Rebolledo actúa así casi en estrecha coincidencia con la estancia de René Descartes en la corte de Estocolmo, al amparo de la soberana. Véase Rafael González Cañal, "El conde de Rebolledo y la reina Cristina de Suecia: una amistad olvidada”, Tierras de León, XXVI, 62 (1986), pp. 93-108. 